\title{
Planar Ultrawideband Antenna with Photonically Controlled Notched Bands
}

\author{
Drasko Draskovic, Jean Raphaël Olivier Fernandez, and César Briso Rodríguez
}

Universidad Politécnica de Madrid, 28031 Madrid, Spain

Correspondence should be addressed to Drasko Draskovic; drasko.draskovic@upm.es

Received 7 December 2012; Accepted 29 January 2013

Academic Editor: Diego Caratelli

Copyright (C) 2013 Drasko Draskovic et al. This is an open access article distributed under the Creative Commons Attribution License, which permits unrestricted use, distribution, and reproduction in any medium, provided the original work is properly cited.

\begin{abstract}
A design of a planar microstrip-fed ultrawideband (UWB) printed circular monopole antenna with optically controlled notched bands is presented. The proposed antenna is composed of a circular ultrawideband patch, with an etched T-shaped slot controlled by an integrated silicon switch. The slot modifies the frequency response of the antenna suppressing $3.5-5 \mathrm{GHz}$ band when the switch is in open state. The optical switch is controlled by a low-power near-infrared $(808 \mathrm{~nm})$ laser diode, which causes the change in the frequency response of the antenna generating a frequency notch. This solution could be expanded to include several notches in the antenna frequency response achieving a fully reconfigurable UWB antenna. The antenna could be remotely controlled at large distances using optical fiber. The prototype antenna has been fully characterized to verify these design concepts.
\end{abstract}

\section{Introduction}

Ultrawideband (UWB) antennas with filtering properties are demanded in many practical applications, owing to the coexistence of UWB systems with other wireless standards, such as WLAN (5.15-5.35 and 5.725-5.825 GHz), WiMAX (3.5 GHz), X-band downlink satellite communication systems $(7.25-7.75 \mathrm{GHz})$, or ITU $(8.025-8.4 \mathrm{GHz})$. The antenna with filtering properties is employed in order to mitigate the devastating interference as well as to remove the requirement of additional bandstop filters. Reconfigurable antennas can have reconfigurable frequency, radiation pattern, polarization, or a combination of these properties. Planar antennas with reconfigurable band notches have been proposed [1-3]. Notched bands were introduced using split ring resonators (SRRs) and complementary split ring resonators (CSRRs). Electronic switches were mounted across or along the resonators to activate the corresponding band notches. Optical switches were introduced in the designs of the frequency and beam reconfigurable antenna [4] and frequency reconfigurable antenna [1]. The ultrawideband planar antenna with photonically controlled notched bands using silicon switch is presented in this paper.
Photonic devices have been considered enabling technologies for future RF and microwave devices and subsystems. The research of optically controlled microstrip switches started in 1970s [5, 6] and is continuing throughout to today. References have reported devices fabricated from coplanar waveguides and microstrip transmission lines printed on silicon substrate $[7,8]$. Simple microwave switches have been applied in designs of antennas, filters, phase shifters, and couplers [9-11]. The main advantage of optically controlled microwave circuits is high level of isolation between the controlling electronic circuit and the microwave circuit. Typically the highly resistive silicon wafer in these devices is illuminated by a near-infra-red laser or a light-emitting diode (LED), with the optical power of few milliwatts. Devices that have proved themselves ideal for implementation of silicon switches are reconfigurable antennas and cryogenic components [12]. The main advantage in reconfigurable antenna design is the elimination of biasing lines that can modify the radiation pattern of the antenna. Several notches controlled with optical switches can be easily included in one antenna to control the frequency response and radiation pattern. 


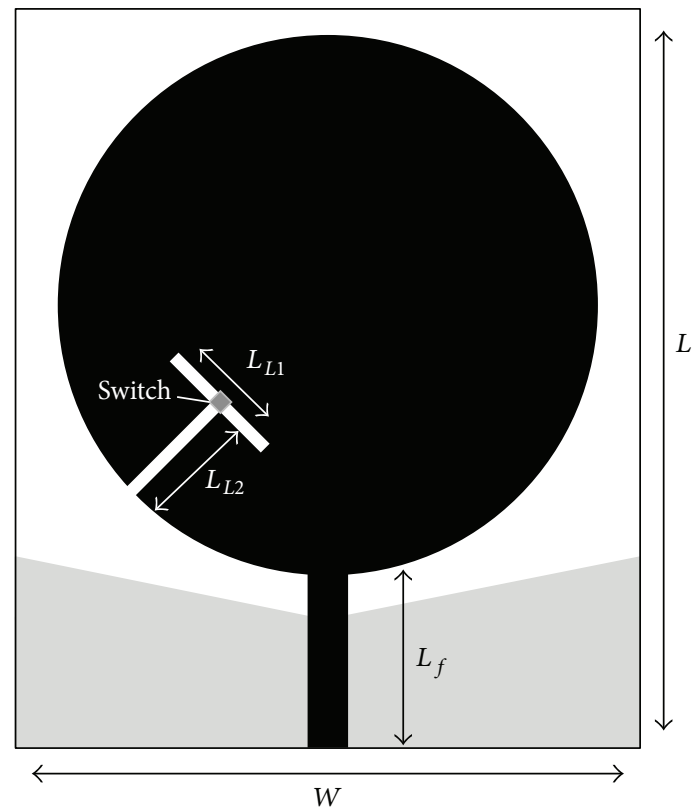

FIgURE 1: The design geometry of the proposed ultrawideband antenna.

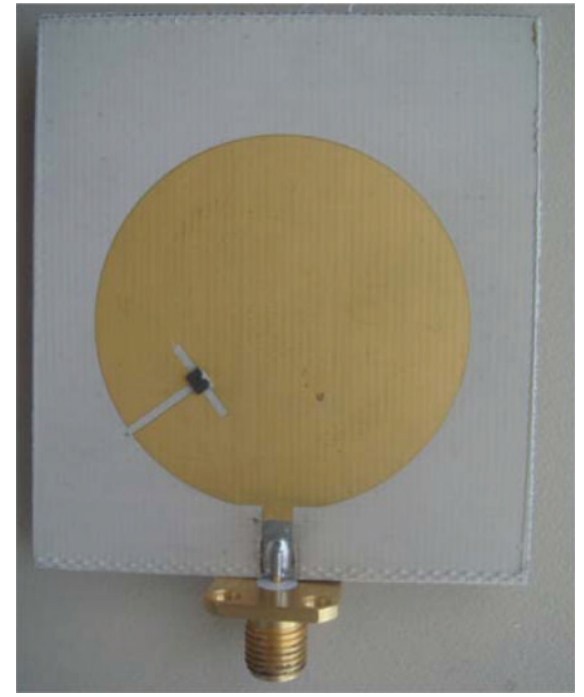

(a)

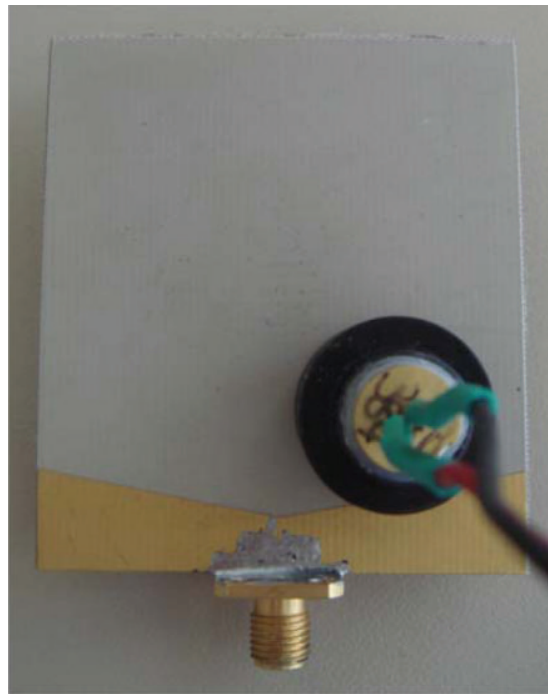

(b)

FIGURE 2: Front and back views of the antenna prototype.

\section{Antenna Design}

The design presented in this paper, shown in Figure 1, is based on the design of a monopole UWB antenna with an etched Tshaped slot and with a partial ground plane designed to be used for UWB from 3.1 to $10.6 \mathrm{GHz}$. The antenna is based on a Taconic substrate with the dielectric constant 3.5 and thickness of $1.524 \mathrm{~mm}$. The radius of the circle is $18.3 \mathrm{~mm}$, and the other dimensions are as follows: $L=50 \mathrm{~mm}, W=50 \mathrm{~mm}$, $L_{f}=7.5 \mathrm{~mm}, L_{L 1}=11.7 \mathrm{~mm}$, and $L_{L 2}=8.6 \mathrm{~mm}$.

The antenna includes a slot controlled with the optical switch. This slot can be designed to generate a notch at the desired frequency, and also the bandwidth of the notch can be controlled with the resistivity of the switch. It is also possible to introduce additional slots that would result in multiple notches.

The optical switch is made placing a silicon dice over the slot of the resonator. The dimensions of the dice of silicon wafer are $1 \mathrm{~mm} \times 1 \mathrm{~mm}$. When the switch is mounted, the slot resonator is causing the band notch in a frequency response of the antenna when the laser diode is turned off and the switch is in OFF state. When the laser diode is activated and the switch is in ON state, the additional resonance is cancelled 


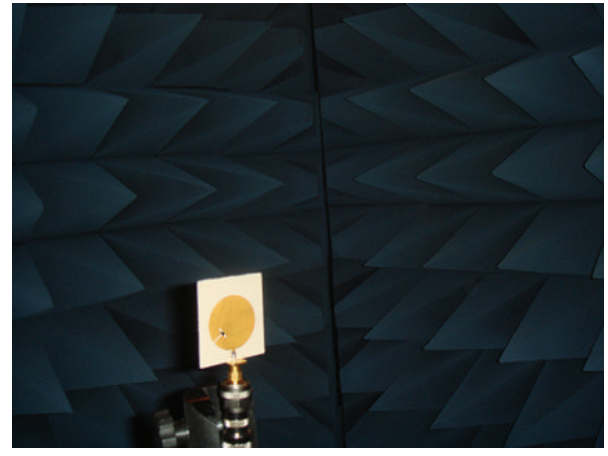

FIGURE 3: Antenna measurement in the anechoic chamber.

Reflection coefficient magnitude versus frequency

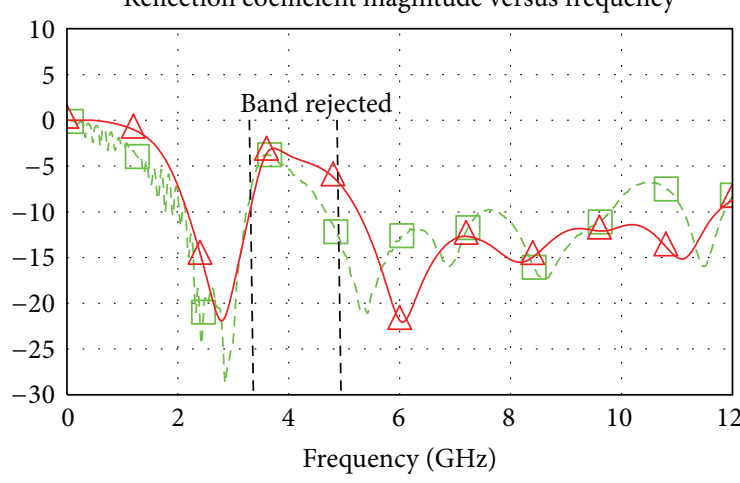

$\triangle \mathrm{DB}(|\mathrm{S}(1,1)|)$ simulation results

DB $(|S(1,1)|)$ measurement results

FIGURE 4: Simulation and measurement of return loss of the antenna when the switch is OFF and the slot generates a notch from 3.5 to $5 \mathrm{GHz}$.

and the notch disappears. In this case, antenna operates in full ultrawideband frequency range.

The dice is made of highly resistive silicon placed on the top of the microstrip gap and photoinduced with a nearinfrared laser diode. The silicon wafer used in the design is highly resistive (around 6,000 $\mathrm{Ohm} \mathrm{cm}$ ), type $\mathrm{N}$, doped with Phosphorus, with 111 crystal orientation, $0.3 \mathrm{~mm}$ thick, single side polished. The light was focused using a $200 \mathrm{~mW} 808 \mathrm{~nm}$ near-infrared laser diode module attached to the back of the ground of the antenna. A $0.5 \mathrm{~mm}$ hole was drilled through the substrate, which allows laser light to reach silicon dice. A prototype shown in Figure 2 was fabricated to verify the performance.

\section{Simulation and Experimental Results}

Electromagnetic simulations of the ultrawideband antenna were performed using CST Studio Suite, and the switch was modelled with different material conductivities for OFF and ON states. Switch conductivities were 10 and $350 \mathrm{~S} / \mathrm{m}$, respectively. These values of switch conductivities were extracted from the measurements of the individual switch placed over a gap of a $50^{\prime} \Omega$ microstrip transmission line built on the same

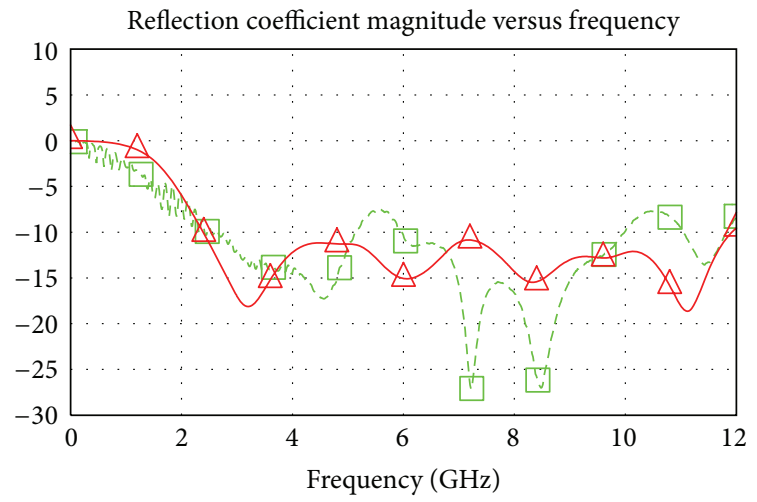

$\triangle \mathrm{DB}(|\mathrm{S}(1,1)|)$ simulation results

$\mathrm{DB}(|\mathrm{S}(1,1)|)$ measurement results

Figure 5: Simulation and measurement of return loss of the antenna when the switch is ON, and the slot disappears. The antenna covers all UWB from 3.1 to $10 \mathrm{GHz}$.

TABLE 1: Gain versus frequency with and without notch.

\begin{tabular}{lcc}
\hline Frequency & Notch “on" gain & Notch “off” gain \\
\hline $3.1 \mathrm{GHz}$ & $2.5 \mathrm{~dB}$ & $2.7 \mathrm{~dB}$ \\
$4 \mathrm{GHz}$ & $-3 \mathrm{~dB}$ & $3.0 \mathrm{~dB}$ \\
$6.85 \mathrm{GHz}$ & $3 \mathrm{~dB}$ & $3.5 \mathrm{~dB}$ \\
$10 \mathrm{GHz}$ & $2.1 \mathrm{~dB}$ & $2.2 \mathrm{~dB}$ \\
\hline
\end{tabular}

TABLE 2: Polarization purity change in presence of T-slot.

\begin{tabular}{lc}
\hline Frequency & Polarization purity change $(\mathrm{dB})$ \\
\hline $3.1 \mathrm{GHz}$ & $0.96 \mathrm{~dB}$ \\
$5.66 \mathrm{GHz}$ & $3.28 \mathrm{~dB}$ \\
$6.85 \mathrm{GHz}$ & $2.72 \mathrm{~dB}$ \\
\hline
\end{tabular}

substrate. Measurements of the antenna were performed in the anechoic chamber as shown in Figure 3. Antenna return loss simulation and measurement results are shown in states when the switch is OFF and ON in Figures 4 and 5. It can be clearly seen in Figure 4 how the band from 3.5 to $5 \mathrm{GHz}$ is rejected when the switch is $\mathrm{ON}$ and the antenna is working from 3.1 to $10.6 \mathrm{GHz}$ with return losses better than $10 \mathrm{~dB}$ that fulfils the FCC criterion [13].

Gain, efficiency, and radiation pattern measurements of the antenna at different frequencies were performed in a large far field anechoic chamber. The results of the gain measured with and without notch are given in Table 1. Gain significantly reduces when the notch is activated. The average efficiency of the antenna is $70 \%$ and reduces to $60 \%$ when the switch is $\mathrm{ON}$. We performed measurements of the influence of Tslot on polarization purity by measuring antenna polarization purity with slot and without it. The results are summed up in Table 2. We found that in both cases antenna exhibits good polarization purity.

The simulated and measured E-plane- and H-planenormalized radiation patterns at $3.1 \mathrm{GHz}$ and $6.85 \mathrm{GHz}$ for 


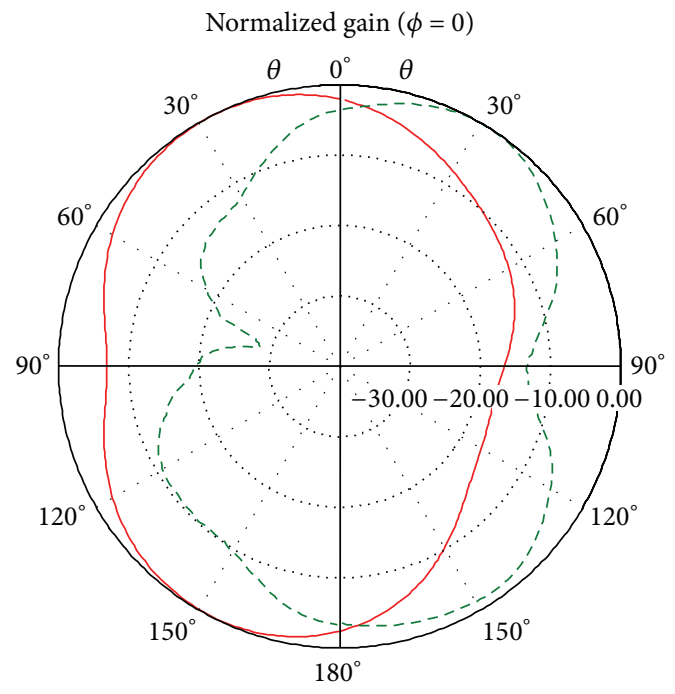

$\theta\left({ }^{\circ}\right)$ versus $(\mathrm{dBi})$

Frequency $=3.1 \mathrm{GHz}$

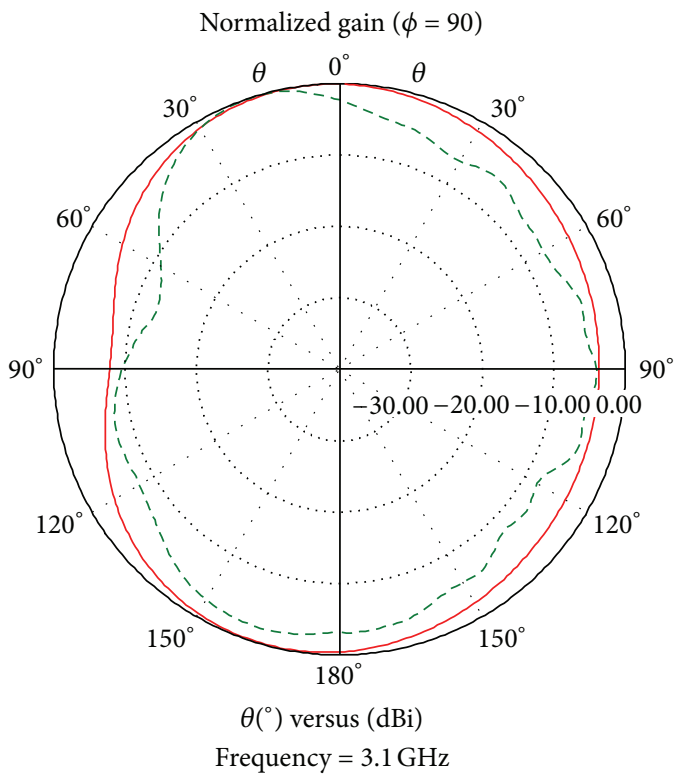

(a)

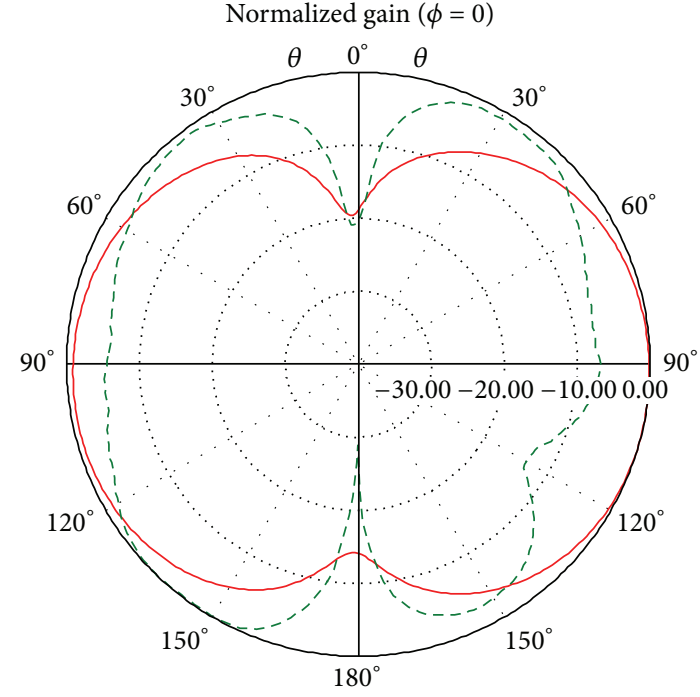

$\theta\left({ }^{\circ}\right)$ versus $(\mathrm{dBi})$

Frequency $=6.85 \mathrm{GHz}$

Normalized gain $(\phi=90)$

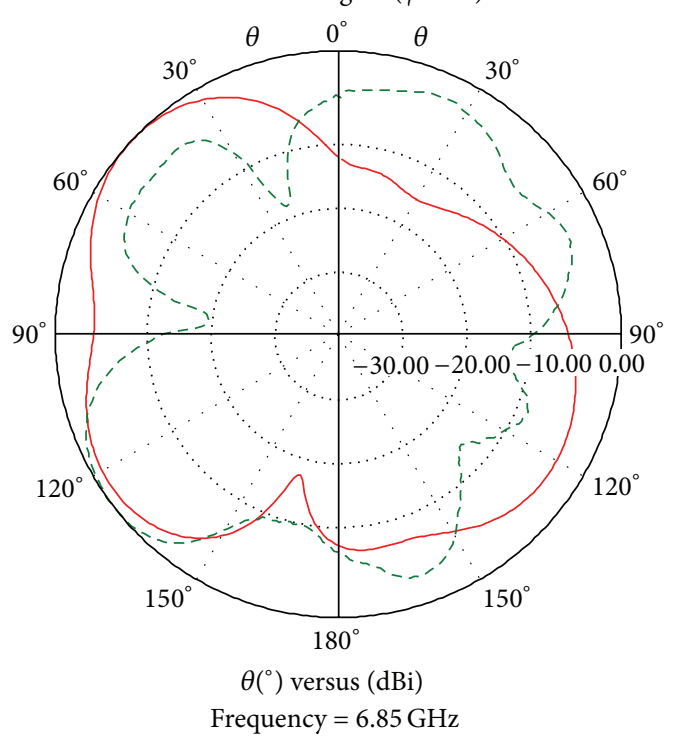

(b)

FIGURE 6: Simulated (solid) and measured (dashed) E-plane and H-plane radiation patterns for the center frequency: (a) $3.1 \mathrm{GHz}$ and (b) $6.85 \mathrm{GHz}$ for OFF state of the switch.

both switch states are plotted in Figures 6 and 7, respectively. Radiation pattern is quite omnidirectional and fits fairly well with CST simulations. There are some differences that can be caused by the feeding SMA connector and small parasitic capacitance $(0.2 \mathrm{pF})$ of the silicon switch.

\section{Conclusion}

The design of a new ultrawideband monopole antenna with an etched T-shaped slot with integrated silicon switch and photonically controlled band notch has been presented. The photoconductive silicon switch was mounted across the Tshaped slot resonator and used to activate and deactivate the notch in the antenna response.

The main advantage of this ultrawideband antenna with filtering properties is the elimination of the undesired band. In our case a 3.5 to $5 \mathrm{GHz}$ band has been chosen, and a controlled reduction of the antenna gain has been achieved. The band notch switching has been successfully demonstrated through simulation and measurements. The other advantage of this reconfigurable ultrawideband antenna is the elimination of biasing lines that could interfere with the operation of the antenna. Applications requiring sensing 


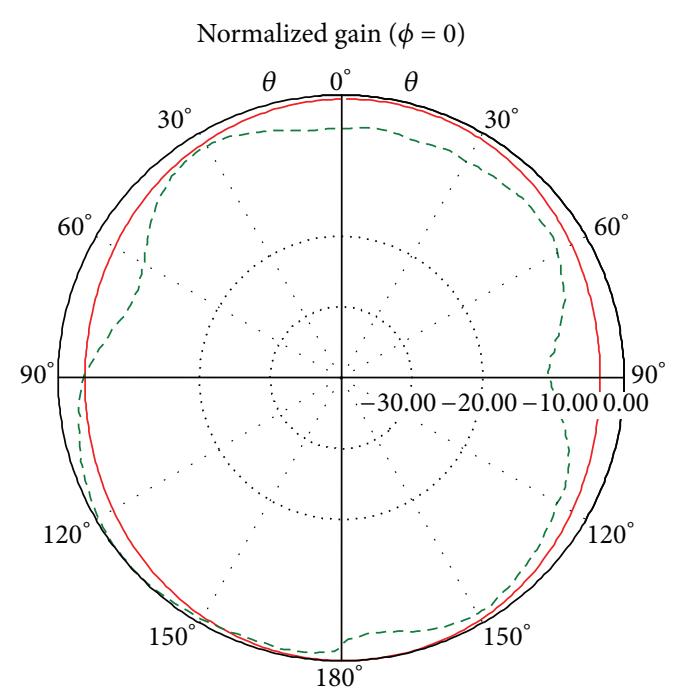

$\theta\left({ }^{\circ}\right)$ versus $(\mathrm{dBi})$

Frequency $=3.1 \mathrm{GHz}$

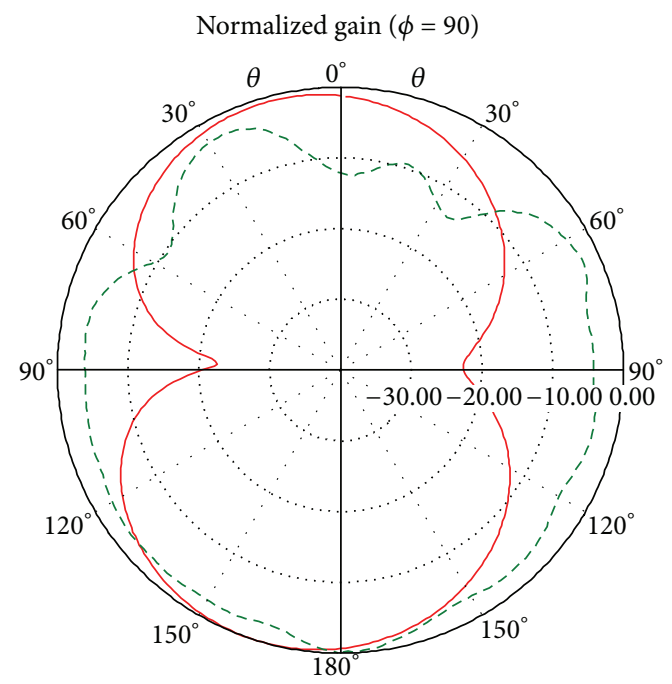

$\theta\left({ }^{\circ}\right)$ versus $(\mathrm{dBi})$

Frequency $=3.1 \mathrm{GHz}$

(a)

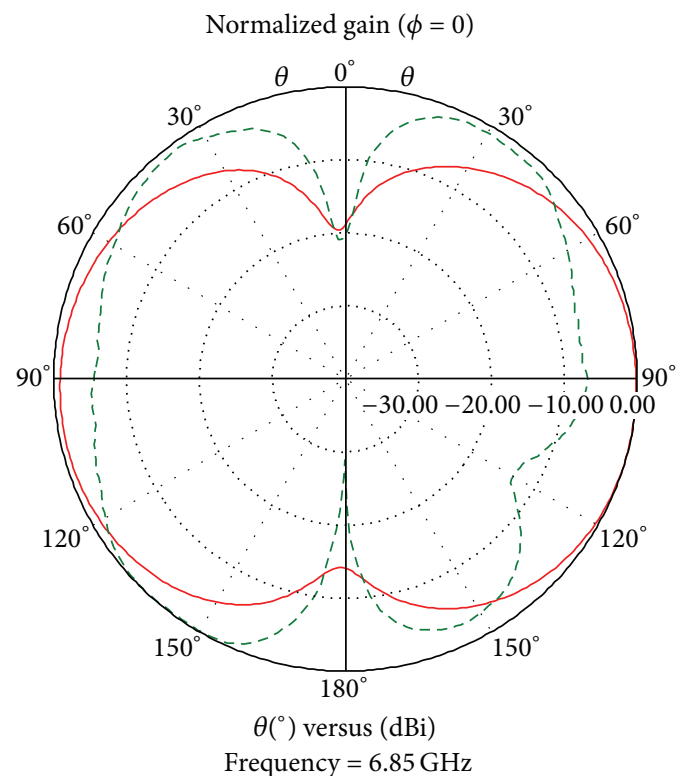

Normalized gain $(\phi=90)$

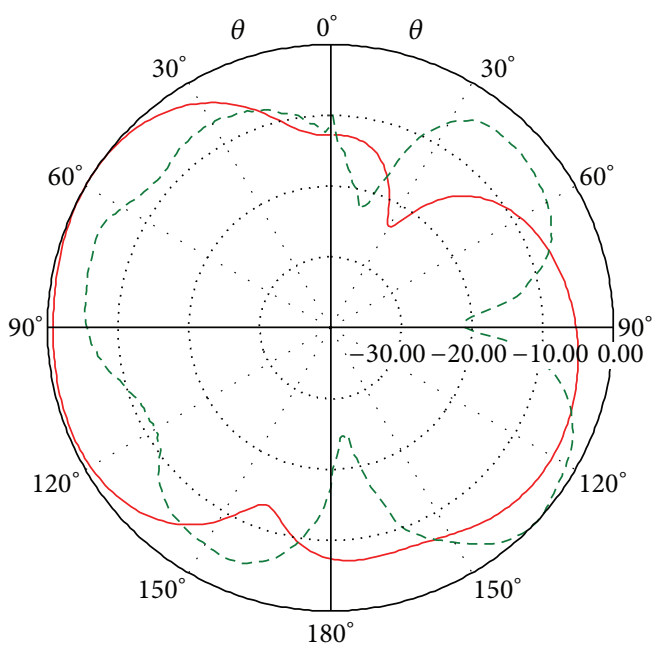

$\theta\left(^{\circ}\right)$ versus $(\mathrm{dBi})$

Frequency $=6.85 \mathrm{GHz}$

(b)

FIGURE 7: Simulated (solid) and measured (dashed) E-plane and H-plane radiation patterns for the center frequency: (a) 3.1 GHz and (b) $6.85 \mathrm{GHz}$ for ON state of the switch.

and frequency band switching such as cognitive radio could benefit from the proposed reconfigurable antenna.

\section{References}

[1] Y. Tawk, A. R. Albrecht, S. Hemmady, G. Balkrishnan, and C. G. Christodoulou, "Optically pumped frequency reconfigurable antenna design," IEEE Antennas and Wireless Propagation Letters, vol. 9, pp. 280-283, 2010.

[2] Y. Zhang, W. Hong, C. Yu, Z. Q. Kuai, Y. D. Don, and J. Y. Zhou, "Planar ultrawideband antennas with multiple notched bands based on etched slots on the patch and/or split ring resonators on the feed line," IEEE Transactions on Antennas and Propagation, vol. 56, no. 9, pp. 3063-3068, 2008.
[3] M. Al-Husseini, J. Costantine, C. G. Christodoulou, S. E. Barbin, A. El-Hajj, and K. Y. Kabalan, "A reconfigurable frequencynotched UWB antenna with split-ring resonators," in Proceedings of Asia-Pacific Microwave Conference (APMC '10), pp. 618621, December 2010.

[4] C. J. Panagamuwa, A. Chauraya, and J. C. Vardaxoglou, "Frequency and beam reconfigurable antenna using photoconducting switches," IEEE Transactions on Antennas and Propagation, vol. 54, no. 2, pp. 449-454, 2006.

[5] D. H. Auston, "Picosecond optoelectronic switching and gating in silicon," Applied Physics Letters, vol. 26, no. 3, pp. 101-103, 1975.

[6] W. Platte, "Spectral dependence of microwave-power transmission in laser-controlled solid-state microstrip switches," IEE 
Journal on Solid-State and Electron Devices, vol. 2, no. 4, pp. 97$103,1978$.

[7] J. R. Flemish and R. L. Haupt, "Optimization of a photonically controlled microwave switch and attenuator," IEEE Transactions on Microwave Theory and Techniques, vol. 58, no. 10, pp. 25822588, 2010.

[8] Y. Horii and M. Tsutsumi, "Scattering parameters of semiconductor microstrip line under laser spot illumination," in Proceedings of the IEEE MTT-S International Microwave Symposium Digest, vol. 1-3, pp. 1675-1678, June 1996.

[9] D. Draskovic, C. Panagamuwa, J. C. Vardaxoglou, and D. Budimir, "Frequency reconfigurable RF circuits using photoconducting switches," International Journal of RF and Microwave Computer-Aided Engineering, vol. 20, no. 1, pp. 15-21, 2010.

[10] D. Draskovic, C. Panagamuwa, D. Budimir, and J. C. Vardaxoglou, "Frequency switchable dual-band branch-line couplers," in Proceedings of the 39th European Microwave Conference (EuMW '09), pp. 133-136, Rome, Italy, October 2009.

[11] D. Draskovic and D. Budimir, "Optically reconfigurable dualband compact branch-line couplers," in Proceedings of the 2nd European Conference on Antennas and Propagation (EuCAP '07), pp. 11-16, Edinburgh, UK, November 2007.

[12] K. F. Raihn, N. O. Fenzi, E. R. Soares, and G. L. Matthaei, "Optical switch for high temperature superconducting microwave band reject resonators," in Proceedings of the IEEE MTT-S International Microwave Symposium, vol. 1-3, pp. 187-190, May 1995.

[13] C. H. Lee, P. S. Mak, and A. P. DeFonzo, "Optical control of millimeter-wave propagation in dielectric wave-guides," IEEE Journal of Quantum Electronics, vol. 16, no. 3, pp. 277-288, 1980. 

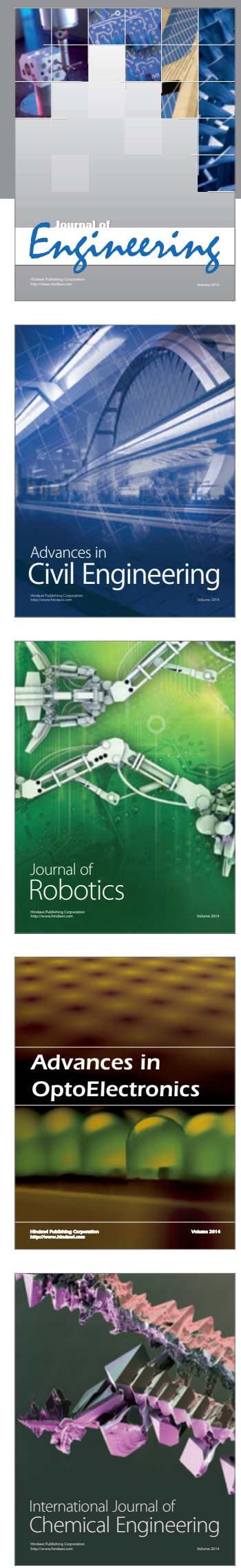

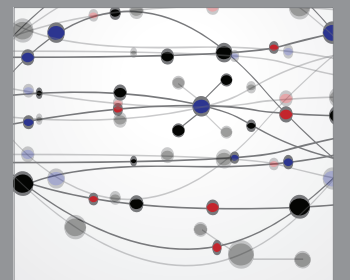

The Scientific World Journal
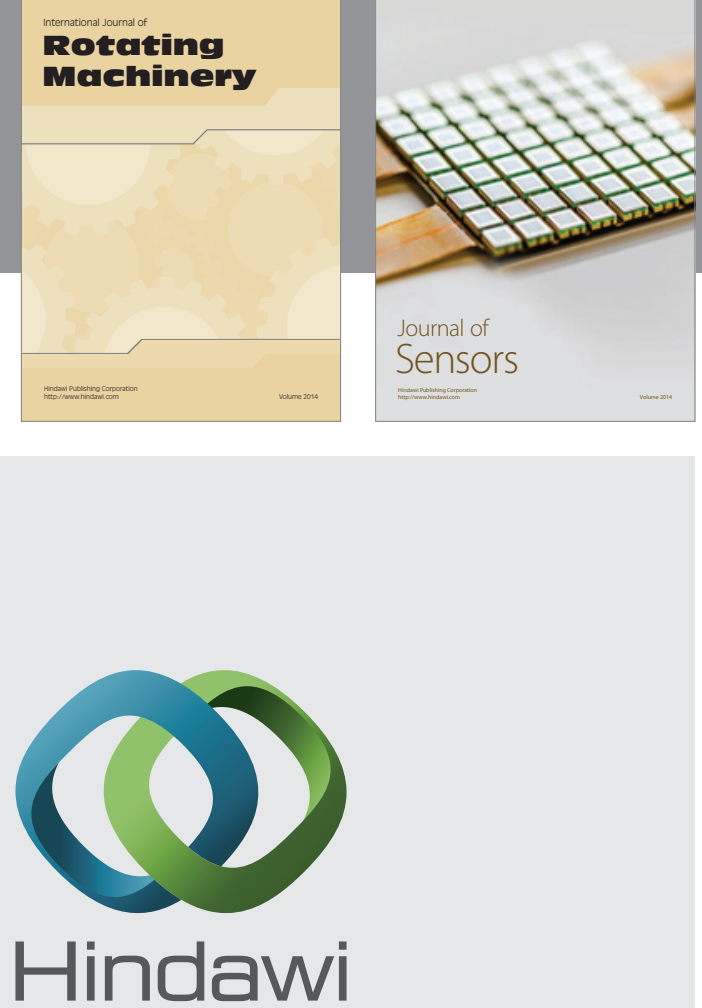

Submit your manuscripts at http://www.hindawi.com
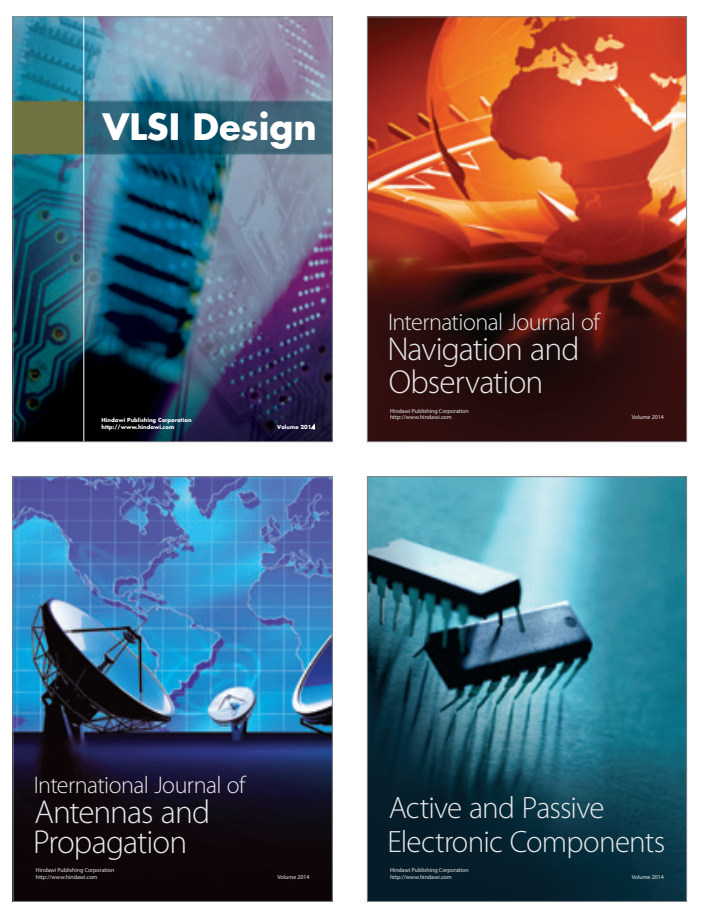
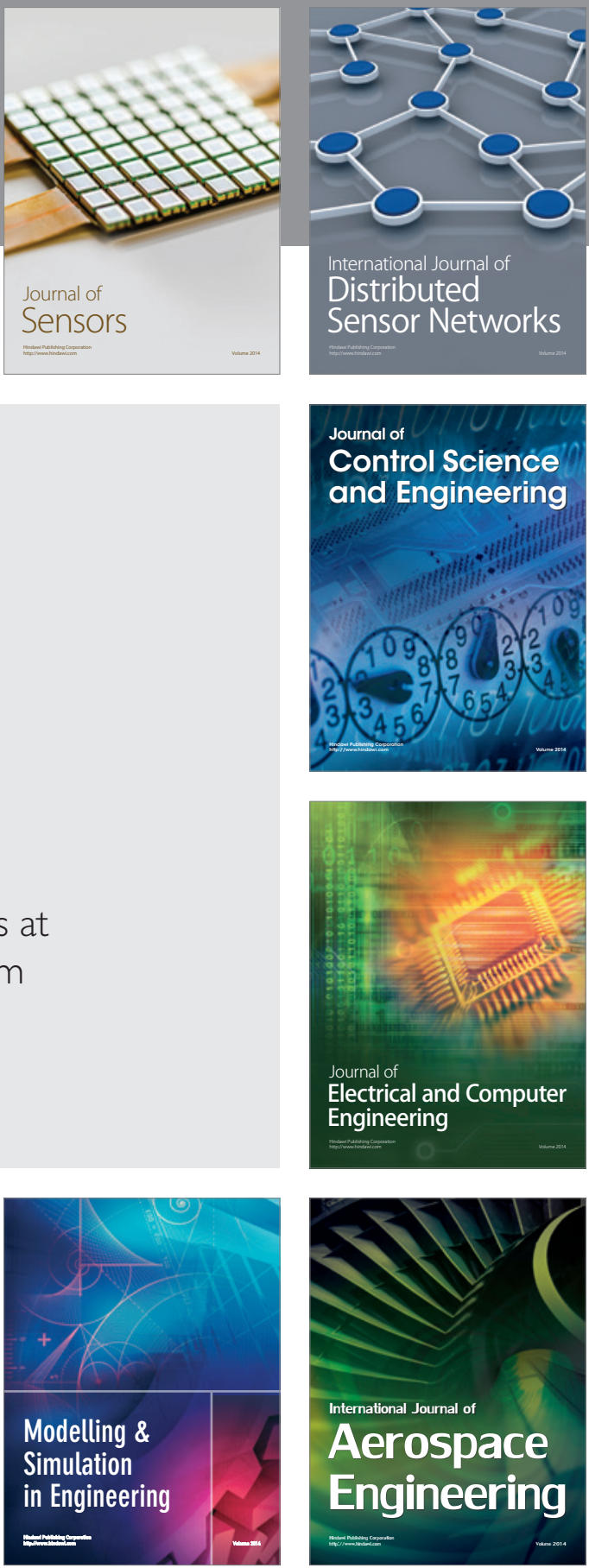

Journal of

Control Science

and Engineering
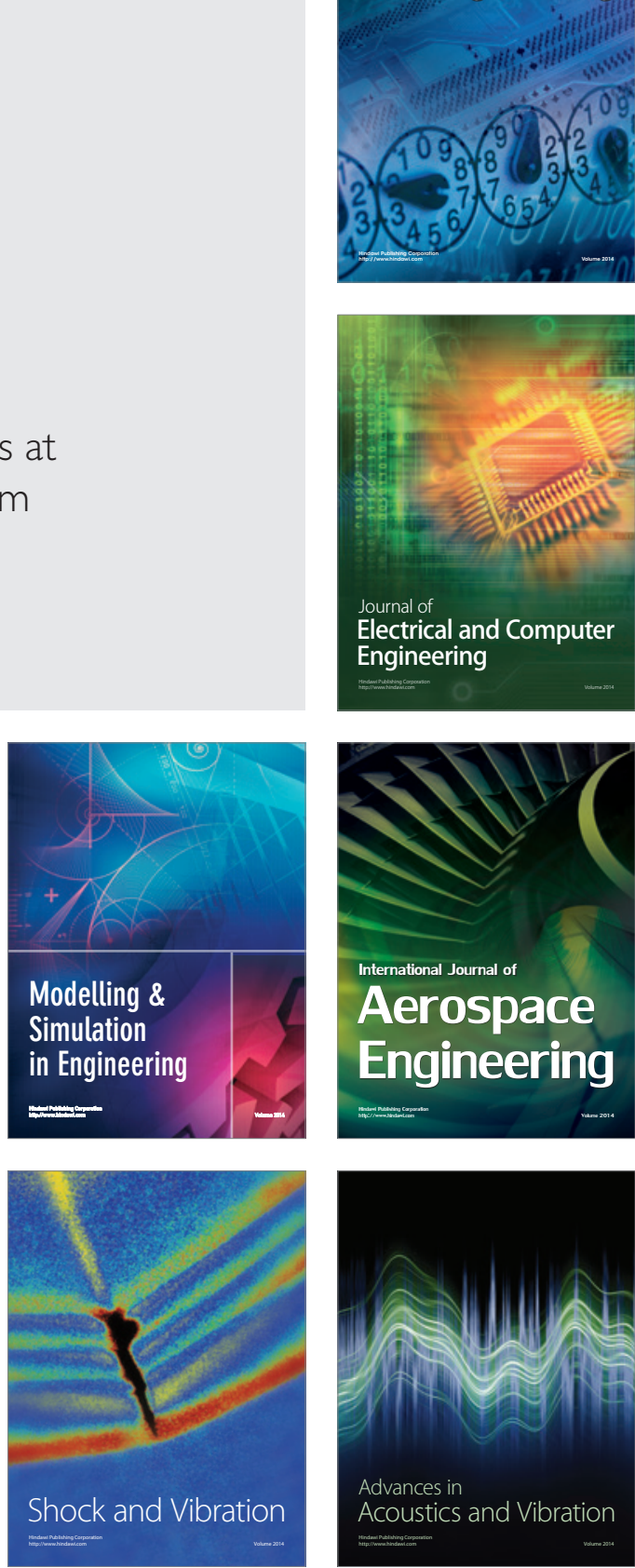